\title{
Association between strengths use and psychological adjustment to visual impairments among visually impaired individuals
}

Shinichiro Matsuguma

Keio Gijuku Daigaku

Motoko Kawashima ( $\square$ motoko326@gmail.com )

Keio University https://orcid.org/0000-0001-7650-7180

Masahiko Ayaki

Keio Gijuku Daigaku

Kazuo Tsubota

Keio Gijuku Daigaku

\section{Research}

Keywords: Psychological adjustment, Strengths use, Positive psychology, Visual impairments

Posted Date: February 4th, 2020

DOI: https://doi.org/10.21203/rs.2.22637/v1

License: (c) (i) This work is licensed under a Creative Commons Attribution 4.0 International License. Read Full License 


\section{Abstract}

\section{Background:}

We investigated the association between strengths use and psychological adjustment to visual impairment among the visually impaired individuals to identify the possibility of using one's strengths to facilitate their psychological adjustment to visual impairment.

\section{Methods:}

Fifty-nine visually impaired individuals (mean age: $49.3 \pm 14.8$ years; range: $22-82$ ) were assessed using the Strengths Use Scale and the Japanese version of the Nottingham Adjustment Scale (anxiety/depression, self-esteem, attitude to disability, acceptance of disability, locus of control, and selfefficacy). The participants' sociodemographic and their visual impairment-related information were also collected.

\section{Results:}

A simple regression analysis of the Nottingham Adjustment Scale scores revealed that strengths use was significantly correlated with anxiety/depression, self-esteem, self-efficacy, and acceptance of VI, while multiple regression analyses identified strengths use as the most significant factor correlated with anxiety/depression, self-esteem, and self-efficacy.

\section{Conclusions:}

Strengths use could be a promising means of facilitating better psychological adjustment to visual impairment, although further study is needed to examine the underlying mechanisms involved.

\section{Introduction}

Visual impairment $(\mathrm{VI})$ is known as a deteriorating factor of psychological well-being among the visually impaired individuals (Nyman, Dibb, Victor, \& Gosney, 2012; Garcia et al., 2017; Berman \& Brodaty, 2006; Ribeiro et al., 2015; Lam, Christ, Lee, Zheng, \& Arheart, 2008; Scott, Smiddy, Schiffman, Feuer, \& Pappas, 1999). Previous literature indicates that $\mathrm{VI}$ is associated with emotional distress (Berman \& Brodaty, 2006), depression (Ribeiro et al., 2015), suicide risk (Lam et al., 2008), and social isolation (Scott et al., 1999). Therefore, it is important for the visually impaired individuals to adjust to VI psychologically to promote their quality of life. However, psychological adjustment (PA) to $\mathrm{VI}$, or acceptance a disability is a lifelong process (Tuttle \& Tutle, 2004). Traditionally, the five-stage model of grief process is often applied to understand this psychological adjustment including the stages of denial, anger, bargaining, depression, and acceptance (Giarratana-Oehler, 1976). To facilitate this process of acceptance effectively, Suzukamo et al. (2001) articulate that PA to disability consists of multiple psychological dimensions: depression/anxiety, self-esteem, self-efficacy, acceptance of VI, locus of control, and attitude toward 
disability. Therefore, improving each of these dimensions would be effective to facilitate PA to $\mathrm{VI}$ and achieve their psychological flourishing.

With these six dimensions in mind, positive psychology might play a significant role in facilitating this effective psychological adjustment. Positive psychology is a scientific study of what makes life worth living (Seligman \& Csikszentmihalyi, 2001). It is a science of human strengths, which are positive traits that reflect universal capacities for thinking, feeling, and behavior in ways that benefit oneself and others, and produce valued outcomes (Peterson \& Seligman, 2004). Much research shows that strengths use is associated with lower depression (Seligman, Steen, Park, \& Peterson, 2005), higher self-esteem (Govindji \& Linley, 2007), self-efficacy (Govindji \& Linley, 2007), and higher subjective well-being (Proctor, Maltby, \& Linley, 2011) among the healthy samples. Furthermore, strengths use is also positively correlated with subjective happiness (Matsuguma, Kawashima, Negishi, Sano, Mimura, \& Tsubota, 2018) and selfesteem (Matsuguma, Kawashima, Sano, \& Tsubota, in press) even among the visually impaired individuals. Based on these findings in the field of positive psychology, utilizing one's strengths might be able to facilitate PA to VI among the visually impaired individuals more effectively.

Furthermore, when it comes to PA to $\mathrm{VI}$, self-image is also related to this effective psychological adjustment. Ueda (2017) argues that psychological reactions would be different, depending on how much his/her self-concept was deteriorated by VI. If a person with VI constructs negative self-image and resists change, it could become very challenging to promote PA to VI in rehabilitation. Therefore, whether the visually impaired individuals could gain new behaviors and adjust to their new life might partially depend on their self-concept. In this sense, strengths in positive psychology might also be beneficial since strengths can guide individuals to define their identity from a place of positive assets, helping them to overcome their selective attention on problems and deficits (Rashid \& Seligman, 2018).

In order to investigate the possibility of strengths use for facilitating PA to VI among the visually impaired individuals, we conducted a research on the association between strengths use and PA to VI among the persons with VI in a cross-sectional manner. We hypothesized that strengths use would be associated with better PA to VI regardless of VI-related factors such as duration or severity of VI. To test this hypothesis, we examined the correlation between each of the six dimensions of PA to VI and their strengths use as well as VI-related factors.

\section{Methods}

\section{Participants and setting}

This study was part of a nested research project titled, "Survey of positive psychological aspects among the individuals with VI." The study data were drawn from a survey conducted from January to September 2017. Fifty-nine persons with VI, legally classified based on the Japanese Physically Disabled Persons Welfare Act, were recruited to participate in this study from several welfare institutions in the Kanto area, Japan, including the Japan Vocational Development Center for the Blind and the following non-profit organizations: Turtle, SPAN, and Hikarinomori. Participants were excluded if they were aged less than 20 
years. Their mean age was $49.3 \pm 14.8$ (range: $22-82$ ) years, and $35.6 \%$ were women $(n=21)$. All of them utilized the above institutions seeking for social support such as job training and socialization.

The institutional review board at Keio University School of Medicine approved the research protocol, which followed the tenets of the Declaration of Helsinki. Informed consent was obtained from all individual participants included in the study.

\section{Measures}

Strengths use was assessed by the Japanese version of the Strengths Use Scale (SUS); the 14 SUS items were evaluated on a five-point Likert scale (ranging from 1-5, total range 14-70), with higher values corresponding to more frequent strengths use (Govindji, \& Linley, 2007). The Japanese scale demonstrates good internal consistency $(a=0.94)$ and satisfactory test-retest reliability $(r=0.67)$ over four weeks (Takahashi \& Morimoto, 2015). PA to disability was evaluated by the Japanese version of the Nottingham Adjustment Scale (NAS-J), comprising six categories: anxiety/depression, self-esteem, selfefficacy, acceptance of VI, locus of control, and attitude toward disability (Suzukamo et al., 2001; Dodds, Flannigan, \& Ng, 1993). Scores for each category are calculated and adjusted individually. Total possible scores range from 0 to 100, with higher scores indicating greater adjustment. Each of the components demonstrates good internal consistency: anxiety/depression ( $a=.84)$, self-esteem ( $a=0.76)$, self-efficacy $(a=0.80)$, acceptance of VI $(a=0.75)$, locus of control $(a=0.51)$, and attitude toward blindness $(a=$ 0.73) (Suzukamo et al., 2001).

We also collected the participants' sociodemographic and visual information to examine the co-founding factors, including sex, age, better eye-corrected visual acuity, worse eye-corrected visual acuity, legal Japanese VI grade (Grades 1-5, with lower grades indicating greater VI severity), history of VI (congenital/acquired), duration of VI (years), education (high school or lower/beyond high school), employment status (employed/unemployed/temporarily leave), annual income ( $<2$ million/ $\geq 2$ million, < 4 million/ $\geq 4$ million, $<6$ million/ $\geq 6$ million), systemic diseases (yes/no with specification), living independently (living alone/living with family), and support for daily activities (yes/no with specification).

\section{Data Analysis}

Data obtained from the participants' questionnaires were statistically analyzed. For corrected visual acuity, the values for counting fingers, hand motion, light perception, and no light perception were set at $0.002,0.004,0.001$, and 0.0005 , respectively. Simple regression analysis was performed to examine the association between the NAS-J and SUS scores as well as other sociographic and VI-related factors. Multiple regression analysis was subsequently conducted to identify the most significant independent predictors of NAS-J scores. The significance level was set at $P<0.05$ for all analyses, which were performed using SPSS version 24 for Windows (SPSS Inc., Chicago, IL, USA).

\section{Results}


A total of 59 individuals with VI participated in the study. The mean score of the SUS was $48.6 \pm 10.7$ (range: 23-68) and the mean score of each category of NAS-J was as follows: anxiety/depression (75.5 \pm 20.9, range: $16.67-100)$; self-esteem ( $52.8 \pm 25.0$, range: $6.25-100)$; self-efficacy (63.6 \pm 21.3 , range: 0 $100)$; acceptance of VI (53.2 \pm 22.3 , range: 8.3-95.8); locus of control (71.3 \pm 19.2 , range: 16.6-100); and attitude to disability $(36.9 \pm 21.2$, range: $0-93.75)$.

Regarding the VI-related factors, $22.0 \%(n=13)$ were congenital and $88.1 \%$ were severely impaired (Grade $1: \mathrm{n}=35$; Grade 2: $\mathrm{n}=17$; Grade 3: $\mathrm{n}=1$; Grade 4: $\mathrm{n}=3$; and Grade $5: \mathrm{n}=3$ ). The mean VI duration was $22.1 \pm 13.4$ (range: $2-68$ ) years, and their better and worse eye-corrected visual acuity (logMAR) were $2.23 \pm 0.94(0.52-3.30)$ and $2.60 \pm 0.87(0.05-3.30)$, respectively. Regarding their sociodemographic profile, $78 \%(n=46)$ had graduated from high school or higher education. Regarding their employee status, $44.1 \%(n=26)$ were employed while $49.2 \%(n=29)$ were unemployed and $6.8 \%(n=4)$ were on temporary leave. When it comes to the annual income, $28.8 \%(n=26)$ earned less than 2 million yen; 44.1\% $(n=43)$ earned between 2 and 4 million; 15.3\% $(n=9)$ earned between 4 and 6 million, and $11.9 \%$ $(n=7)$ earned more than 6 million. 33.9\% $(n=20)$ lived alone, and $66.1 \%(n=39)$ lived with family members. In addition, $55.9 \%$ of them $(n=33)$ received support for daily activities. $33.9 \%(n=24)$ claimed systemic diseases such as depression $(n=2)$, chronic pancreatitis $(n=3)$, diabetes $(n=7)$, high blood pressure $(n=5)$, chronic pain $(n=2)$, orthopedic disease $(n=2)$, hearing loss $(n=2)$, and atopic dermatitis $(n=1)$.

\section{Associations between strengths use (SUS) and psychological adjustment to disability (NAS-J)}

To investigate the association between strengths use and PA to $\mathrm{VI}$, we conducted a simple regression analysis to identify significant factors affecting each of the dimensions of NAS-J. The results are shown in Table 1, and the associations between SUS and each of the NAS-J components are illustrated in Figure 1.

Table 1. Simple regression analysis for the association between Nottingham Adjustment Scale Japanese version and other variables 


\begin{tabular}{|c|c|c|c|c|c|c|}
\hline & \multicolumn{6}{|c|}{$\bar{B}$} \\
\hline $\begin{array}{l}\text { Dependent } \\
\text { Variables }\end{array}$ & $\begin{array}{c}\text { Anxiety } \\
\text { depression }\end{array}$ & $\begin{array}{c}\text { Self- } \\
\text { esteem }\end{array}$ & $\begin{array}{c}\text { Self- } \\
\text { efficacy }\end{array}$ & $\begin{array}{l}\text { Acceptance } \\
\text { of } \\
\qquad \text { VI } \\
\end{array}$ & $\begin{array}{c}\text { Locus } \\
\text { of }\end{array}$ & $\begin{array}{l}\text { Attitude to } \\
\text { disability }\end{array}$ \\
\hline SUS & $0.44^{* *}$ & $0.56^{* *}$ & $0.44^{* *}$ & $0.42^{* *}$ & 0.23 & 0.10 \\
\hline Age & $0.38^{* *}$ & $0.33^{*}$ & -0.09 & -0.18 & -0.03 & -0.14 \\
\hline $\operatorname{Sex}^{A}$ & -0.13 & -0.20 & $0.32 *$ & 0.17 & -0.04 & 0.22 \\
\hline BCVA & 0.17 & 0.17 & 0.09 & 0.00 & 0.00 & 0.04 \\
\hline WCVA & -0.07 & -0.10 & 0.04 & 0.04 & 0.08 & -0.00 \\
\hline History of $\mathrm{VI}^{\mathrm{B}}$ & 0.03 & $0.43^{* *}$ & 0.08 & 0.21 & 0.06 & -0.05 \\
\hline Duration of VI & $0.06^{*}$ & $0.43^{* *}$ & 0.02 & 0.06 & -0.03 & 0.09 \\
\hline $\begin{array}{l}\text { Disability } \\
\text { grades }\end{array}$ & 0.19 & -0.03 & -0.08 & -0.01 & 0.07 & 0.11 \\
\hline $\begin{array}{l}\text { Systemic } \\
\text { diseases }^{C}\end{array}$ & -0.04 & 0.03 & 0.14 & 0.16 & 0.09 & 0.17 \\
\hline $\begin{array}{l}\text { Live } \\
\text { independently } \mathrm{D}\end{array}$ & -0.07 & 0.16 & 0.12 & -0.01 & 0.23 & -0.06 \\
\hline $\begin{array}{l}\text { Support for } \\
D^{E}{ }^{E}\end{array}$ & 0.01 & -0.20 & -0.22 & 0.03 & -0.15 & -0.04 \\
\hline Education $^{F}$ & 0.23 & 0.10 & -0.03 & -0.18 & 0.09 & 0.05 \\
\hline $\begin{array}{l}\text { Employment } \\
\text { status }^{\mathrm{G}}\end{array}$ & -0.29 & -0.20 & -.008 & 0.16 & -0.01 & -0.25 \\
\hline Annual income $\mathrm{H}^{\mathrm{H}}$ & 0.25 & 0.02 & -0.09 & -0.02 & 0.11 & 0.16 \\
\hline
\end{tabular}

${ }^{A}$ male $=1$, female $=2 ;{ }^{B}$ congenital $=1$, acquired $=2 ;{ }^{C}$ no systemic disease $=0$, presence of any systemic diseases $=1 ;{ }^{D}$ living alone $=1$, living with family $=2 ;{ }^{E}$ presence of any support for daily activities $=1$, no support for daily activities $=2,{ }^{F}$ high school or lower $=1$, beyond high school $=2 ;{ }^{\mathbf{G}}$ employed $=1$, unemployed $=2$, temporarily leave $=3 ;{ }^{H}<2$ million $=1, \geq 2$ million $/<4$ million $=2, \geq 4$ million $/<6$ million $=3, \geq 6$ million $=4$.

Abbreviations, SUS: Strengths Use Scale; Vl: visual impairment; BCVA: better eye-corrected visual acuity; WCVA: worse eye-corrected visual acuity. ${ }^{*} P<0.05 .{ }^{* \star} P<0.01$.

We identified that the SUS score was significantly associated with anxiety/depression, self-esteem, acceptance of $\mathrm{Vl}$, and self-efficacy, respectively. In contrast, there was no significant association between the SUS score and locus of control as well as attitude to disability.

Our subsequent multiple regression analysis tested the most significant independent variables related to each of the items of NAS-J since several significant factors were identified in the simple regression analysis with anxiety/depression, self-esteem, and self-efficacy (Table 2). This analysis identified that the SUS score was the most significant factor affecting anxiety/depression, self-esteem, and self-efficacy in the NAS-J. 
Table 2. Multiple regression analysis for the association between Nottingham Adjustment Scale Japanese version and selected variables

\begin{tabular}{|c|c|c|c|}
\hline & $\beta$ (P-Value) & & \\
\hline Dependent Variables & Anxiety/depression & Self-esteem & Self-efficacy \\
\hline SUS & $0.31 *(0.02)$ & $0.48^{* *}(<0.001)$ & $0.38 * *(<0.001)$ \\
\hline Age & $0.23(0.07)$ & $0.14(0.30)$ & - \\
\hline $\operatorname{Sex}^{A}$ & - & - & $0.21(0.09)$ \\
\hline Duration of $\mathrm{VI}$ & $0.12(0.36)$ & $0.26(0.06)$ & - \\
\hline History of $\mathrm{VI}^{\mathrm{B}}$ & - & $-0.09(0.49)$ & - \\
\hline Employment status ${ }^{c}$ & $-0.11(0.41)$ & - & - \\
\hline
\end{tabular}

${ }^{A}$ male $=1$, female $=2 ;{ }^{B}$ congenital $=1$, acquired $=2{ }^{c}$ employed $=1$, unemployed $=2$, temporarily leave $=3$.

Abbreviations, SUS: Strengths Use Scale; Vl: visual impairments. ${ }^{*} P<0.05 .{ }^{*} P<0.01$.

\section{Discussion}

In this present study, we demonstrated a close correlation between strength use and PA to VI in visually impaired individuals. We believe our findings are noteworthy since most previous studies failed to consider their positive assets, only focusing on the negative effect of VI.

This significant association between strengths use and PA could be explained based on the several advantages of strengths. First, the positive effect of strengths use could have nothing to do with VI. In cases of depression, previous studies show that strengths use could decrease depressive symptoms among healthy (Seligman et al., 2005) and diseased subjects (Seligman, Rashid, \& Parks, 2006). Moreover, Govindji and Linley (2007) indicate the positive association between strengths use and both self-esteem and self-efficacy among healthy populations while Leontopoulou and Triliva (2012) report that character strength was significantly associated with self-acceptance among a healthy sample. In the area of $\mathrm{VI}$, we also indicate that strengths use was positively associated with subjective happiness and positive emotions among individuals with $\mathrm{Vl}$, regardless of their visual condition (Matsuguma et al., 2018). Since strengths theory in positive psychology is derived from the personality traits theory, external physical restrictions are irrelevant to the context of strengths use. Therefore, the present study could identify significant associations between strengths use and PA with respect to anxiety/depression, selfesteem, acceptance of disability, and self-efficacy, even among the individuals with VI. 
The second explanation is that strengths use could function as a protective factor from the negative effects of VI. While previous literature indicates a negative association between $\mathrm{VI}$ and psychological well-being (Nyman et al., 2012; Garcia et al., 2017; Berman \& Brodaty, 2006; Ribeiro et al., 2015; Lam et al., 2008; Scott et al., 1999; Senra et al., 2015), many studies in the field of positive psychology claim that using strengths is energizing (Biswas-Diener, 2010) and focusing on the positive assets in persons with disabilities could generate positive emotions for building resilience (Dana, Gitendra, Timothy, Alissa, \& Brittany, 2013). In addition, Peters et al. (2017)demonstrate that positive psychology intervention could improve pain intensity and pain control in persons with chronic pain. Therefore, strengths use might protect the visually impaired individuals from the negative effect of VI.

Based on the present results, integration of strengths or positive psychology intervention might be beneficial to promote PA in visually impaired individuals. There has been abundant research on strengthsbased positive psychology intervention to improve psychological well-being (Gander, Proyer, Ruch, \& Wyss, 2013; Ghielen, van Woerkom, \& Christina, 2017), and in the field of ophthalmology, we also report that strengths intervention could improve eye-related QOL in patients with eye pain (Matsuguma, Kawashima, Uchino, \& Tsubota, 2018) as well as self-esteem among the visually impaired individuals (Matsuguma, et al., in press). With these findings in mind, positive psychology intervention might be a promising support to facilitate PA to VI among the visually impaired individuals.

Although most of the components of PA to VI were correlated with strengths use, additional investigations are needed to understand how strengths use is associated with locus of control and attitude to disability. Regarding the locus of control, since all of the participants utilized social support such as a vocational institution, they perhaps more readily recognized the importance of receiving support from others than believing in their independency, thereby yielding this outcome. For attitude to disability, the association might be attributed to the descriptions of this item, which mainly asks the respondents to consider the attitude of the visually impaired individuals in general, rather than their individual, specific attitude. Therefore, as many previous studies report the negative effects of VI (Nyman et al., 2012; Garcia et al., 2017; Berman \& Brodaty, 2006; Ribeiro et al., 2015; Lam et al., 2008; Scott et al., 1999; Senra et al., 2015), our participants might have responded accordingly without considering their own personal attitudes. Future studies are needed to determine the contribution of these two components of PA to $\mathrm{VI}$.

There are several limitations of this study. One of them is the small sample size given the estimated total number of people with VI in Japan, which is approximately 1,640,000 (Yamada et al., 2010). The second limitation is that this study did not include a control group. The result might have been different if we had conducted with the visually impaired individuals in rural areas or other countries because of the lack of social support or cultural differences. Hence, this finding might not reflect the overall population with VI. Nevertheless, since the association between strengths use and PA to VI was noticeably more significant than any other sociographic and VI-related factors, our finding can indicate that strengths use is a promising way to promote PA in individuals with VI. Having said that, the nature of the cross-sectional 
design in this present analysis could not identify causal relationships between strengths use and PA among people with $\mathrm{VI}$. A longitudinal research is required to verify this causality in the future.

In conclusion, this study identified strengths use as the most significant factor associated with most of the components of PA to VI such as anxiety/depression, self-esteem, acceptance of disability, and selfefficacy. Since PA to VI is crucial for improving psychological well-being among the visually impaired individuals, strengths use might contribute to this adjustment process more effectively, using their own positive assets.

\section{Declarations}

\section{Ethics approval and consent to participate:}

All procedures performed in studies involving human participants were in accordance with the ethical standards of the institutional and/or national research committee (The institutional review board at Keio University School of Medicine, UMIN000025337) and with the 1964 Helsinki declaration and its later amendments or comparable ethical standards. Informed consent was obtained from all individual participants included in the study.

\section{Consent for publication:}

Yes

\section{Availability of data and material:}

The datasets generated and/or analyzed during the current study are available from the corresponding author on reasonable request.

\section{Competing interests:}

The authors declare that they have no conflict of interest.

\section{Funding:}

None

\section{Authors' contributions:}

SM designed, collected and analyzed the data. MK, YA, and TK provided advice on the results and the composition of the manuscript. All authors read and approved the final manuscript.

\section{Acknowledgments:}

We are grateful for the kind assistance of Mitsuko Sakata (Japan Vocational Development Center for the Blind), Haruo Matsuzaka (NPO Turtle), Akira Kitagami (NPO SPAN), and Kazuko Matsuda (NPO 
Hikarinomori) who supported this study by recruiting, collecting data, and providing anonymized data to Keio University from each institution.

\section{References}

Berman, K., \& Brodaty, H. (2006). Psychosocial effects of age-related macular degeneration. International Psychogeriatrics, 18, 415-428.

Biswas-Diener, R. (2010). Practicing positive psychology coaching: Assessment, activities and strategies for Success. New Jersey, NJ: John Wiley \& Sons, Inc.

Dana, S.D., Gitendra, U., Timothy, R.E., Alissa, L., \& Brittany, B. (2013). A positive psychology of physical disability: Principles and progress. In M.L. Wehmeyer (Ed.), The oxford handbook of positive psychology and disability (pp. 427-441). New York, NY: Oxford University Press.

Dodds, A.G., Flannigan, H., \& Ng, L. (1993). The Nottingham Adjustment Scale: a validation study. International Journal of Rehabilitation Research, 16, 177-184.

Gander, F., Proyer, R.T., Ruch, W., \& Wyss, T. (2013). Strength-based positive interventions: Further evidence for their potential in enhancing well-being and alleviating depression. Journal of Happiness Studies, 14, $1241-1259$.

Garcia, G.A., Khoshnevis, M., Gale, J., Frousiakis, S.E., Hwang, T.J., Poincenot, L. ... Sadun A.A. (2017). Profound vision loss impairs psychological well-being in young and middle-aged individuals. Clinical Ophthalmology, 11. 417-427.

Ghielen, S.T.S., van Woerkom, M., \& Christina, M.M. (2017). Promoting positive outcomes through strengths interventions: A literature review. Journal of Positive Psychology, 1-13.

Giarratana-Oehler, J. (1976). Personal and professional reactions to blindness from diabetic retinopathy. New Outlook for the Blind, 70, 237-239.

Govindji, R., \& Linley, P.A. (2007). Strengths use, self-concordance and well-being: Implications for strengths coaching and coaching psychologists. International Coaching Psychology Review, 2, 143-153.

Lam, B.L., Christ, S.L., Lee, D.J., Zheng, D.D., \& Arheart, K.L. (2008). Reported visual impairment and risk of suicide: the 1986-1996 national health interview surveys. Archives of Ophthalmology, 126, 975-980.

Leontopoulou, S., \& Triliva, S. (2012). Explorations of subjective wellbeing and character strengths among a Greek University student sample. International Journal of Wellbeing, 2, 251-270.

Matsuguma, S., Kawashima, M., Negishi, K., Sano, F., Mimura, M., \& Tsubota, K. (2018). Strengths use as a secret of happiness: Another dimension of visually impaired individuals' psychological state. PLoS One. https://doi.org/10.1371/journal.pone.0192323 
Matsuguma, S., Kawashima, M., Sano, F., \& Tsubota, K. (in press). "Cannot see? Use your strengths!" A randomized controlled trial of strengths intervention for improving self-esteem among visually impaired individuals. Clinical Rehabilitation.

Matsuguma, S., Kawashima, M., Uchino, M., \& Tsubota, K. (2018). Value of considering psychological strengths in patients with eye pain. American Journal of Ophthalmology Case Reports, 12, 91-92.

Nyman, S.R., Dibb, B., Victor, C.R., \& Gosney, M.A. (2012). Emotional well-being and adjustment to vision loss in later life: a meta-synthesis of qualitative studies. Disability and Rehabilitation, 34, 971-981.

Peters, M.L., Smeets, E., Feijge, M., van Breukelen, G., Andersson, G., Buhrman, M., \& Linton, S. J. (2017). Happy despite pain: A randomized controlled trial of an 8-week internet-delivered positive psychology intervention for enhancing well-being in patients with chronic pain. The Clinical Journal of Pain, 33, 962975.

Peterson, C., \& Seligman, M.E.P. (2004). Character strengths and virtues: A handbook and classification. New York, NY: Oxford University Press.

Proctor, C., Maltby, J., \& Linley, P.A. (2011). Strengths use as a predictor of well-being and health-related quality of life. Journal of Happiness Studies, 12, 153-169.

Rashid T., \& Seligman, M.E.P. (2018). Positive psychotherapy: Clinical manual. New York, NY: Oxford University Press.

Ribeiro, M.V., Hasten-Reiter Junior, H.N., Ribeiro, E.A., Jucá, M.J., Barbosa, F.T., \& Sousa-Rodrigues, C.F. (2015). Association between visual impairment and depression in the elderly: a systematic review. Arquivos Brasileiros de Oftalmologia, 78, 197-201.

Scott, I.U., Smiddy, W.E., Schiffman, J., Feuer, W.J., \& Pappas, C.J. (1999). Quality of life of low-vision patients and the impact of low-vision services. American Journal of Ophthalmology, 128, 54-62.

Seligman, M.E.P., and Csikszentmihalyi, M. (2000). Positive psychology: An introduction. American Psychologist, 55, 5-14.

Seligman, M.E.P., Rashid, T., \& Parks, A.C. (2006). Positive psychotherapy. American Psychologist, 61, 774788.

Seligman, M.E.P., Steen, T.A, Park, N., \& Peterson, C. (2005). Positive psychology progress: empirical validation of interventions. American Psychologist, 60, 410-421.

Senra, H., Barbosa, F., Ferreira, P., Vieira, C.R., Perrin, P.B., Rogers, H., Rivera, D., \& Leal, I. (2015). Psychologic adjustment to irreversible vision loss in adults: a systematic review. Ophthalmology, 122, 851-861. 
Suzukamo Y, Kumano H, Iwaya R. Development and validation of "The Nottingham Adjustment Scale Japanese Version" which measures psychological adjustment to the visual impairment. Shinshinigaku. 2001, 41:609-618. [Japanese]

Takahashi, M., \& Morimoto, Y. (2015). [Development of Japanese version of the Strength Use Scale (SUS).] Japanese Journal of Research on Emotions, 22, 94-99. [Japanese]

Tuttle, D.W., \& Tuttle, N.R. (2004). Self-esteem and adjusting with blindness: The process of responding to life's demands. Illinois, IL: Charles C Thomas Pub Ltd.

Ueda, U. (2017). Psychosocial adaptation to visual impairment, causes and coping with visual impairment and blindness. IntechOpen. Retrieved from https://www.intechopen.com/books/causes-andcoping-with-visual-impairment-and-blindness/psychosocial-adaptation-to-visual-impairment

Yamada, M., Hiratsuka, Y., Roberts, C.B., Pezzullo, M.L., Yates, K., Takano, S. ... Taylor, H.R. (2010). Prevalence of visual impairment in the adult Japanese population by cause and severity and future projections. Ophthalmic Epidemiology, 17, 50-57.

\section{Figures}


\section{Figure 1}


Simple regression analysis results for association between Strengths Use Scale and components of the Nottingham Adjustment Scale Japanese version. Four (anxiety/depression, self-esteem, self-efficacy, and acceptance of $\mathrm{VI}$ ) of six components of the Nottingham Adjustment Scale were significantly correlated with SUS. Abbreviations; Vl: visual impairment; SUS: Strengths Use Scale. 